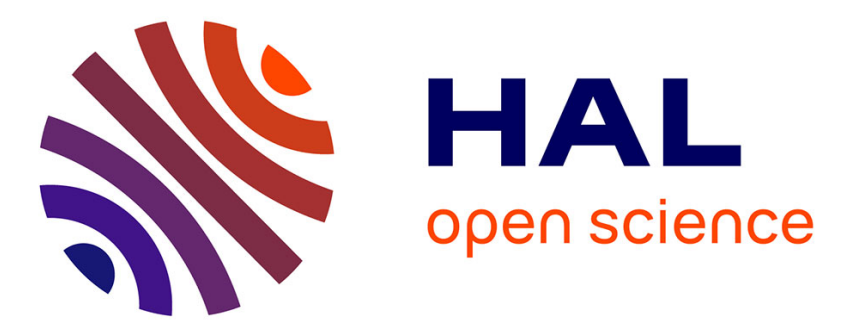

\title{
Morphology and composition of Au catalysts on Ge(111) obtained by thermal dewetting
}

S Hajjar, G Garreau, L Josien, Jean-Luc Bubendorff, D Berling, A Mehdaoui, C Pirri, T Maroutian, C Renard, D Bouchier, et al.

\section{- To cite this version:}

S Hajjar, G Garreau, L Josien, Jean-Luc Bubendorff, D Berling, et al.. Morphology and composition of $\mathrm{Au}$ catalysts on $\mathrm{Ge}(111)$ obtained by thermal dewetting. Physical Review B: Condensed Matter and Materials Physics (1998-2015), 2011, 84 (12), pp.125325. 10.1103/PhysRevB.84.125325 . hal01122603

\section{HAL Id: hal-01122603 \\ https://hal.science/hal-01122603}

Submitted on 4 Mar 2015

HAL is a multi-disciplinary open access archive for the deposit and dissemination of scientific research documents, whether they are published or not. The documents may come from teaching and research institutions in France or abroad, or from public or private research centers.
L'archive ouverte pluridisciplinaire HAL, est destinée au dépôt et à la diffusion de documents scientifiques de niveau recherche, publiés ou non, émanant des établissements d'enseignement et de recherche français ou étrangers, des laboratoires publics ou privés. 
Morphology and composition of Au catalysts on Ge(111) obtained by thermal dewetting

S. Hajjar, G. Garreau, L. Josien, J. L. Bubendorff, D. Berling, A. Mehdaoui, C. Pirri*. IS2M, Université de Haute Alsace, CNRS-LRC 7228, 68057 Mulhouse, France

T. Maroutian, C. Renard, D. Bouchier

IEF, Université Paris-Sud, UMR 8622, Orsay, F-91405 and CNRS, Orsay, F-91405

M. Petit, A. Spiesser, M. T. Dau, L. Michez, V. Le Thanh

CINaM-CNRS, Aix-Marseille Université, Campus de Luminy, Case 913, 13288 Marseille

Cedex 9

T. O., Mentes, M. A. Nino, A. Locatelli

Sincrotrone Trieste, Area Science Park, Trieste 34012, Italy

PACS numbers: 73.63 Kv, 68.37 Ef, 64.75.Jk, 61.46.-w

\begin{abstract}
:
\end{abstract}
We investigate the chemical and morphological structure of the Au nanodots on $\mathrm{Ge}(111)$ which serve as catalysts for the formation of epitaxial Ge nanowires. The spatial localization of $\mathrm{Au}$ is investigated by X-ray spectromicroscopy and transmission electron microscopy. We show that dewetting of an $\mathrm{Au}$ film on $\mathrm{Ge}(111)$ gives rise to a thin Au-Ge wetting layer and Au-Ge dots. These dots are crystallized but not with a single crystallographic orientation. Thanks to the spatially resolved X-ray and transmission electron microscopy measurements, a chemical characterization of both binary Au-Ge catalysts and wetting layer is obtained at the nanoscale. We show that Ge vertical growth is achieved even without external Ge supply.

\footnotetext{
* Corresponding author. Fax: 0033389336083 Email: carmelo.pirri@uha.fr
} 


\section{Introduction:}

The growth of nanowires by the vapor-liquid-solid (VLS) or vapor-solid-solid (VSS) mechanism is a well-known and very nice bottom-up approach in the fabrication of onedimensional objects, which can be used in a very large variety of devices ${ }^{1-5}$. The experimental VLS approach needs alloys that can form nanoscale catalysts, which melt at low temperatures thanks to the deep eutectic point in the bulk phase diagram. Most interesting is that these alloys are also of interest in the overall microelectronic area as solder materials and in all technological area in which low temperature and corrosion resistance are required, such as space technology, gas sensor and medical devices. The nanowires geometry is ideal for monolithic integration of semiconductor materials with different lattice constants due to their ability to accommodate strain in two dimensions. As to nanowires growth, if an epitaxial growth is required to perform devices, these catalysts are formed under ultrahigh vacuum on a clean and crystalline substrate. In some case, their chemical and morphological properties have been investigated. Nevertheless, the chemical reaction at the interface between the deposited material, which serves to form the catalysts, and the semiconductor surface strongly depends on their chemical nature. This point was extensively and is still studied in the formation of thin layers (two-dimensional) interfaces but it becomes much more complex for surfaces on which dots are formed. On one hand it needs particular tools for local measurements and on the other hand, the reduced size of the catalysts and of the wires grown through it highlights new phenomena. Numerous materials have been tentatively used as catalysts, each with its own influence on the nanowires growth, such as nanowires crystal orientation and growth orientation with respect to the semiconductor surface. Among these catalysts, Au droplets have been extensively used ${ }^{5-42}$ and a particular attention is given at the nanowire/catalyst interface $15,18-20,22,23,26-31$. For other purposes, the $\mathrm{Au} / \mathrm{Ge}(111)$ interface 
below 1 monolayer has thoroughly been investigated by photoemission, Auger electron spectroscopy, LEED and X-ray diffraction ${ }^{43-50}$. It is characterized by the formation of a $\sqrt{3} x$ $\sqrt{ } 3 \mathrm{R} 30^{\circ}$ superstructure (or wetting layer) associated with the formation of Au trimers on

$\operatorname{Ge}(111)^{48-50}$. It is found to be stable at high annealing temperatures, up to the melting point of germanium ${ }^{45}$. In contrast, the $\mathrm{Au} / \mathrm{Ge}(111)$ interface has only poorly been studied for $\mathrm{Au}$ deposits above 1 monolayer. It is worth noting that Au catalysts are generally created by dewetting a pure Au film of about $1 \mathrm{~nm}$ thick and up to now only few papers report on the characterization of the Au droplets before nanowires growth.

In this work, we investigate both chemical and morphological structure of the $\mathrm{Au}$ platelets on $\mathrm{Ge}(111)$, formed by annealing a pure $\mathrm{Au}$ film at a temperature below $300^{\circ} \mathrm{C}$, and of $\mathrm{Au}$ droplets, formed at higher annealing temperature, which serve as catalysts for the formation of epitaxial Ge nanowires. This study is performed by using Scanning Tunneling Microscopy (STM), X-ray Photoemission Spectroscopy (XPS) and X-ray Photo-Diffraction (XPD), Reflection High Energy Electron Diffraction (RHEED), and finally by using X-ray Photoemission Electron Microscopy (X-PEEM) and Transmission Electron Microscopy (TEM) in both image and microanalysis modes.

\section{Experiments.}

The sample preparation, as well as the STM, RHEED and X-rays photoelectron diffraction (XPD) measurements, were performed in UHV setup with a base pressure below 1 x $10^{-10}$ mbar. STM measurements were made in a room-temperature-operating microscope (Omicron STM-AFM microscope), in the constant-current mode. Electrochemically etched, in situ cleaned tungsten tips were used. The Au catalysts were grown on a clean $\mathrm{Ge}(111)$ substrate. The Ge(111) substrate was degassed by direct heating up to $450{ }^{\circ} \mathrm{C}$ for 10 hours 
and flashed afterwards at $720{ }^{\circ} \mathrm{C}$ to remove the native oxide layer. After repeated flashes at $720{ }^{\circ} \mathrm{C}$ for increasing durations (up to one minute), the substrate was cooled rapidly down to $860{ }^{\circ} \mathrm{C}$ and then more slowly (at a rate of $0.5^{\circ} \mathrm{C} / \mathrm{s}$ ) down to RT. STM images taken on a clean $\mathrm{Ge}(111)$ substrate show terraces larger than $200 \mathrm{~nm}$ and a quite defect-free $\mathrm{c}(2 \times 8)$ surface atomic structure. Au catalysts were formed by annealing Au layers evaporated on such a Ge(111) substrate kept at room temperature. An effusion cell was used with a deposition rate of about $0.05 \mathrm{~nm} / \mathrm{min}$. The Au layer thickness was set between 0.6 and $1.2 \mathrm{~nm}$. This $\mathrm{Au}$ amount gave us the opportunity to form $\mathrm{Au}-\mathrm{Ge}$ droplets with a lateral size between 5 and 200 $\mathrm{nm}$, then easily observable by STM for the smallest one, and by SEM and X-ray spectromicroscopy for the largest. The deposition rate is controlled by a water-cooled quartz crystal microbalance and the nominal Au thickness is given with a precision better than $10 \%$. The annealing temperature is monitored with an accuracy of $\pm 20^{\circ} \mathrm{C}$. XPD measurements were carried out using a hemispherical analyzer operating at an angular resolution of $\pm 1^{\circ}$ (Omicron experimental set-up). XPD scans were obtained by measuring the intensity of the $\mathrm{Au} 4 \mathrm{f}$ core level doublet excited with an $\mathrm{Al} \mathrm{K \alpha} \mathrm{x}$-ray source (photon energy $=1486.6 \mathrm{eV}$ ).

The local X-ray spectromicroscopy measurements are performed with the XPEEM-LEEM microscope at Elettra laboratory in Trieste (Italy) on the Nanospectroscopy beamline, which routinely works with spatial resolution of $40 \mathrm{~nm}$ in XPEEM mode. Details on the microscope and the beamline are reported in ref.51, 52. Using synchrotron light as a photon source we were able to select the photon energy for probing both Ge3d and Au4f core level emission under optimal conditions. TEM and EDX were performed with a JEOL 3010 microscope operating at $300 \mathrm{keV}$ with a spatial resolution of about $2 \mathrm{~nm}$.

\section{III) Results and discussions.}


Figure 1a shows an image of a $0.8 \mathrm{~nm}$ thick Au layer deposited at room temperature on $\mathrm{Ge}(111)$. The Au film is rather flat and covers quite uniformly the Ge surface. LEED and RHEED pattern is $1 \times 1$ and shows that $\mathrm{Au}$ is ordered (in epitaxy) on $\mathrm{Ge}(111)$, in agreement with previous findings ${ }^{45,46}$. XPD Au4f $\mathrm{f}_{7 / 2}$ line intensity scans versus polar angle $\theta$ along the [11-2], [-1-12] and [10-1] directions of the Ge(111) crystal are shown in Figure 1b. The polar angle $\theta$ is defined with respect to the surface normal. These intensity modulations versus polar angle show intensity maxima at selected polar angles, consistent with the formation of a facecentered cubic Au structure, with $\mathrm{Au}(111) / / \mathrm{Ge}(111)$, and with [11-2], [-1-12] and [10-1] directions of Au aligned with that of $\mathrm{Ge}(111)$, as observed in ref. 45.

The Au layer is scattered into small islands upon a mild annealing at $300{ }^{\circ} \mathrm{C}$, as shown in Figure 2. This is the first stage of dewetting process. The STM image shows numerous flat platelets with different lateral size and height. Their height varies from 2.5 to $4.5 \mathrm{~nm}$ for a nominal deposit of $0.8 \mathrm{~nm}$ and an annealing at $300^{\circ} \mathrm{C}$ for $10 \mathrm{~min}$. A line scan across two islands is shown in Figure 2. As to their structure, Figure 2 also shows a XPD Au $4 f_{7 / 2}$ profile (a) versus polar angle $\theta$ along the [11-2] direction of the Ge(111) substrate. It is compared to that measured on the room-temperature deposited Au layer (b). This close similarity shows that the Au platelets are still in epitaxy and single-oriented on the Ge(111) substrate. At this stage, an estimation of the Au platelet volume, with respect to the initial Au deposit, suggests that they are quite pure Au. Thus, we may assume here that the bare surface does not significantly contribute to the Au4f modulations versus polar angle. The relevance of this point will be discussed later.

Figure 3 shows a typical STM image acquired after a subsequent anneal at $325^{\circ} \mathrm{C}$ for 10 min. This extra anneal does not change the overall surface morphology. Nevertheless, a close examination shows that several islands have changed their shape. A line scan across these two type of islands clearly shows flat islands and dome-like islands (labeled A and B, 
respectively). The line scan shows that the dome island height is at least twice that of the flat island. The morphology change observed at this temperature can be attributed to the formation of $\mathrm{Au}-\mathrm{Ge}$ droplets at the eutectic composition and thus $\mathrm{Ge}$ incorporation. From bulk Au-Ge phase diagram, the droplet could incorporate 28 at $\% \mathrm{Ge}$ at the eutectic temperature $\mathrm{T}_{\mathrm{E}}$. This would increase the dome-like islands volume of about $33 \%$ if we assume that the bulk phase diagram predictions are still correct for the small droplets and if the Ge incorporated at $\mathrm{T}_{\mathrm{E}}$ remains within the islands at room-temperature. This latter point strongly depends on the time used to decrease the sample temperature from $325^{\circ} \mathrm{C}$ down to roomtemperature. In the present experiments, this time was rather short (less than 5 minutes) and we can assume that the droplet composition is quenched or partially quenched. This point will be also discussed later on the basis of SEM experiments. Upon increasing the annealing temperature up to $350^{\circ} \mathrm{C}$, the surface morphology has completely changed, as evidenced in Figure 4. This STM image is acquired after annealing the surface at $350^{\circ} \mathrm{C}$ for 10 minutes. There is not a track anymore of platelets. All islands have now a dome shape. Upon increasing the annealing time at $350^{\circ} \mathrm{C}$, Ostwald ripening process induced a modification of the sample surface: the islands density is reduced upon increasing annealing time, while their height and diameter increases. In particular, it is shown that the mean droplet diameter increases continuously, quite linearly, versus annealing time, even for durations as long as 12 hours. Figure 5 gives an STM image of the surface after 12 hours annealing at $350^{\circ} \mathrm{C}$. Au droplets as large as $100 \mathrm{~nm}$ are now formed. These droplets are crystallized and show facets. At a first sight, all droplets do not show facets in the same crystallographic direction, as it would be expected for Au island in epitaxy on $\mathrm{Ge}(111)$. A detail view of a droplet is shown in Figure 5. Note that the ripening process is a limiting factor in the fabrication of nanowires with low size dispersion. Despite the well defined crystallographic phases, the $A u 4 f_{7 / 2}$ intensity modulation versus $\theta$ is completely lost on the sample annealed at $350^{\circ} \mathrm{C}$. There is no 
more coherence between the droplets orientation after melt. Such a profile indicates the formation of several nanocrystal orientations, as it is for a polycrystalline surface.

To summarize, an overview of the evolution of the surface morphology versus annealing temperature at a given annealing time, versus annealing time at a given temperature and versus Au layer thickness in a range generally used for nanowires growth is shown in Figure 6. Figure 6A shows a set of STM images taken in the constant current mode for different $\mathrm{Au}$ layer thickness annealed at $350^{\circ} \mathrm{C}\left(\mathrm{T}_{\mathrm{E}}\right)$. Figures $6 \mathrm{~B}, 6 \mathrm{C}$ and $6 \mathrm{D}$ show the mean droplet diameter, the mean droplet height and the droplet density versus annealing duration at $350^{\circ} \mathrm{C}$ for an $\mathrm{Au}$ deposit of $0.8 \mathrm{~nm}$, respectively,. It is shown that the droplet density decreases as the mean droplet diameter and height increases, versus annealing time. In particular, it was shown that the mean droplet diameter increases continuously, quite linearly, versus annealing time, even for durations as long as 12 hours.

Some comment must be given about the in-situ determination of the solid-liquid transition temperature of the droplets. We have chosen to estimate the transition temperature $\mathrm{T}_{\mathrm{E}}$ by using the change on STM images acquired at room temperature. We have determined the temperature at which the platelets transform into dome shape islands (droplets) and assumed that it is $\mathrm{T}_{\mathrm{E}}$, indeed. This temperature is estimated for annealing time longer than 1 hour. As shown below, RHEED can also confirm the structural transition from crystallized platelets (2D crystals) to liquid droplets (3D liquid). RHEED measurement gives complementary and valuable information on the droplets structure. Starting from a clean Ge(111) surface characteristic by a c $(2 \times 8)$ or $(2 \times 1)$ pattern, a (1x1) streaky RHEED pattern is observed for room-temperature Au deposition up to a thickness of $1.2 \mathrm{~nm}$. This indicates that the deposited Au film is relatively flat and epitaxial, in agreement with STM and XPD results. Figure 7A displays a RHEED pattern taken along the [1-10] azimuth of a $1.2 \mathrm{~nm}$ thick $\mathrm{Au}$ film after annealing at $300{ }^{\circ} \mathrm{C}$, i.e. below the eutectic temperature $\mathrm{T}_{\mathrm{E}}$. In contrast with the as- 
deposited pattern, we observe here the appearance of three-dimensional (3D) spots, which can be attributed to the transmission diffraction effect across Au platelets as observed in Fig. 3A. The 3D spots are arranged in a pseudo-hexagonal symmetry and the fact the all these spots are located along the $(1 \mathrm{x} 1)$ streaks confirms that these platelets are coherent and epitaxial. We note that $(1 \mathrm{x} 1)$ streaks are still present, indicating that the Au wetting layer in between platelets remains flat. When annealing at $350^{\circ} \mathrm{C}$ (Fig. 7B), 3D spots are still present but interestingly they are distributed along concentric rings, a behavior similar to that observed from electron diffraction of a polycrystalline structure ${ }^{53-58}$. This is in line with STM measurement, for which it is although difficult to have a good statistics over all orientation of droplets. This is also in good agreement with the above XPD analyses depicted in the curve c of Figure 5, which suggests that, when Au droplets are formed for annealing at temperatures higher than $\mathrm{T}_{\mathrm{E}}$, they are no longer epitaxial but exhibit a random distribution. In other words, upon $\mathrm{Ge}$ incorporation the Au-Ge droplets are no longer made up of (111) planes parallel to the (111) plane of Ge substrate but are randomly oriented.

An important question here is: is there still Au between the platelets and between the droplets and how many $A u$ ? If it is so, this could also participate to the Au4f $\mathrm{f}_{7 / 2}$ modulation versus polar angle. This point has been addressed in the literature a long time ago. Indeed, the formation of the $\mathrm{Au} / \mathrm{Ge}(111)$ interface has been extensively studied in the $0-1 \mathrm{Au}$ monolayer range, in the two past decades. It has been shown that a $\sqrt{3} \times \sqrt{3} \mathrm{R} 30^{\circ}$-Au superstructure appears upon annealing a monolayer Au deposit above $300^{\circ} \mathrm{C}$. This superstructure was found to be stable up to the melting point of $\mathrm{Ge}\left(958.5^{\circ} \mathrm{C}\right)$. Several atomic models have been proposed for this superstructure. For all models, this superstructure consists of a surface on which $\mathrm{Au}$ atoms replace the topmost $\mathrm{Ge}$ atoms of the substrate and form trimers. Au atoms replace either the outermost Ge layer or the second Ge layer. This could be in line with the very low solubility of $\mathrm{Au}$ in $\mathrm{Ge}$, which is less than $10^{-6}$ at\% ${ }^{59-62}$. However, note that interface 
formation is generally out of thermodynamically equilibrium, with the formation of new and metastable phases. Anyway, the nominal amount of $\mathrm{Au}$ involved in this reconstruction is of one Au monolayer. It was also found that this superstructure induces strong distortion in the deeper Ge layers, with most notably a buckling in the third and fourth Ge layers ${ }^{50}$. For very low coverage, the surface periodicity is more complicated since it was observed a "split" (2x2) periodicity along with the $\sqrt{ } 3 \times \sqrt{ } 3$ R $30^{\circ}$ superstructure ${ }^{45}$. For both Au positions on the Ge(111) surface proposed in the literature, the XPS Au4f wave is not expected to experience forward scattering and its contribution would not be detected at polar angles below $60^{\circ}$ in XPS profiles. Some small contribution, as an increase of the mean intensity, would be detected at large polar angles, as it is shown for two-dimensional layers ${ }^{63,64}$. Thus, it can be safely assumed that the "bare surface" does not significantly contribute to the Au4f XPD profiles. The Au4f XPD profiles in Figures 2 and 5 are clearly representative of the $\mathrm{Au}$ droplets or platelets, only. The regime of higher Au coverage (more than 1 Au monolayer) has not been so extensively studied, the focus being on the $\sqrt{3} \times \sqrt{3} \mathrm{R} 30^{\circ}$ itself, due to the universality of its occurrence for the metal/semiconductors interfaces.

Figure 8 shows a SEM image collected at room temperature for a $1.2 \mathrm{~nm}$ Au deposit after anneal at $350^{\circ} \mathrm{C}$ and $400^{\circ} \mathrm{C}$ for 1 hour. This deposit is slightly larger than that used for STM, to be easily observed by SEM. STM shows that increasing the deposit from 0.8 to 1.2 $\mathrm{nm}$ does not significantly change the surface morphology. Figure 8 shows that each droplet is crystallized, as shown by STM. Also shown in Figure 8 is the dispersion in the crystallized droplets shape, in line with randomly oriented nanocrystals, as suggested by RHEED and STM. Furthermore, one can see that the largest droplets are perched on a pedestal after annealing at $350^{\circ} \mathrm{C}$ and $400^{\circ} \mathrm{C}$. This pedestal could be due to precipitated $\mathrm{Ge}$ (or Au-Ge alloy), suggesting that quenching of the droplet composition is not completely efficient. The pedestal has a round form, whatever the nanocrystal shape, which is a reminiscence of the 
liquid droplet form. Similar pedestal has already been observed for Au seeds melt on $\mathrm{Si}(111)$. For the $\mathrm{Au} / \mathrm{Si}(111)$, these pedestals were also attributed to $\mathrm{Si}$ precipitation and thus $\mathrm{Au}$ and $\mathrm{Si}$ phase separation on the basis of selective etching experiments ${ }^{65-67}$. However, the nice experiments reported in ref. 65, 66 do not clarify the crucial point of $\mathrm{Si}$-Au alloy formation and composition. A chemical information has thus to be probed by using spectroscopic investigations at a nanometer scale.

Chemical information on $\mathrm{Au}$ or Au-Ge nanocrystals is gained by using XPEEM and TEM experiments. These techniques are used in both image and spectroscopy modes. EDS spectroscopy used in TEM with a focalized spot allows a good spatial resolution in crosssection images. Nevertheless, due to the large depth probed by the electrons, it is less suitable for a chemical analysis in the in-plane mode. The analysis of the lateral distribution of Au is more convenient by using a tool as nanospectromicroscopy XPEEM.

Figure 9A shows a PEEM image of the sample surface for $1.2 \mathrm{~nm}$ Au deposit annealed at $350{ }^{\circ} \mathrm{C}$ for 12 hours. These experimental conditions are chosen to have droplets large enough to be analyzed since the spatial resolution is about $40 \mathrm{~nm}$ in the XPEEM imaging. This image was acquired in the X-ray absorption mode, at the Ge3d edge. The field of view of this image is $4 \mu \mathrm{m}$. Due to the presence of Ge overall sample surface and due to the large depth probed at this photon energy, all parts of the sample appear with the same grey scale. Nevertheless, thanks to the high photon beam angle, the Au islands are visualized, without significant chemical contrast. The photon beam comes from the bottom-left, with an illumination angle of $74^{\circ}$ with respect to the surface sample. This image shows Au dots with a diameter in the $150-200 \mathrm{~nm}$ range. The topographic contrast is also enhanced by a strong emission of secondary electrons on the bottom-left side of the islands.

The presence of Au atoms between the islands is confirmed by XPEEM. The analysis of the lateral distribution of the interface topmost layer was made by using XPEEM spectral 
imaging. Figure 9A shows a XPEEM image in the XPS mode. In order to maximize surface sensitivity, the photon energy was set to $201 \mathrm{eV}$, corresponding to a kinetic energy of $113 \mathrm{eV}$ of the $\mathrm{Au} 4 \mathrm{f}$ electrons, which is close to the minimum of the inelastic mean free path for this material. The droplets are visualized thanks to the illumination angle and to a slight difference in the Au4f intensity between surface and dots. Figure 9B shows the Au4f line measured on both droplets and surface in between. These spectra show normalized Au4f $f_{7 / 2}$ intensity versus binding energy. The $\mathrm{Au} 4 \mathrm{f}$ binding energy $\mathrm{E}_{\mathrm{B}}$ measured on droplets is almost the same as for bulk $\mathrm{Au}$ at $\mathrm{E}_{\mathrm{B}}=84.0 \pm 0.2 \mathrm{eV}^{49,68-71}$. The binding energy is measured by also scanning across the Fermi level $\mathrm{E}_{\mathrm{F}}$. This suggests that the droplet surface is almost pure Au. The Au4f lines are shifted each other by about $0.45 \mathrm{eV}$. This chemical shift is consistent with that observed for $\mathrm{Au} 4 \mathrm{f}$ measured on the $\mathrm{Ge}(111)-\mathrm{Au} \sqrt{ } 3 \mathrm{x} \sqrt{ } 3 \mathrm{R} 30^{\circ}$ surface and on bulk gold ${ }^{49}$. The droplets, with a mean diameter of $150 \mathrm{~nm}$, are large enough to neglect any final state effect on the Au4f binding energy ${ }^{68-71}$. Note that a straightforward determination of the $\mathrm{Au}$ to $\mathrm{Ge}$ composition cannot be safely extracted from XPEEM data and it would be only a picture of the droplets for a given growth condition. Indeed, it strongly depends not only on the annealing temperature but also on the rate at which the temperature goes down when the sample returns at room temperature. It will be shown below that a strong composition gradient occurs along the surface normal since Ge precipitation is a diffusion limited process. Crosssection TEM images give us more information about the droplet lateral size, the alloyed zone at the $\mathrm{Au} / \mathrm{Ge}(111)$ interface and the alloy extension in the droplet and beneath.

Figure 10 shows TEM images for a $1.2 \mathrm{~nm}$ Au deposit annealed at $350^{\circ} \mathrm{C}(\mathrm{A}),(\mathrm{B})$ and $400^{\circ} \mathrm{C}(\mathrm{C})$. The sample temperature was decreased down to room temperature at of rate higher than $10^{\circ} \mathrm{C} / \mathrm{min}$. These images show Au-Ge droplets of about 50-100 nm lateral size, thus in the range used for XPEEM. It is shown that the dots height, with respect to the surface plane, is larger after annealing at $400^{\circ} \mathrm{C}$ than at $\mathrm{T}_{\mathrm{E}}=340^{\circ} \mathrm{C}$. Most interestingly, the dots 
annealed at low temperature rest on a $1 \mathrm{~nm}$ thick wetting layer with a quite uniform thickness. In contrast, the dots annealed at higher temperature penetrate more deeply in the $\mathrm{Ge}(111)$ substrate. The wetting layer is still observed, with almost the same thickness, but the droplets extent well below the Ge(111)/wetting layer interface. At a first sight, this shows a strong pinning of the droplets when the annealing temperature is increased above $T_{E}$. Such selfpinning effect has also been suggested for the $\mathrm{Au} / \mathrm{Si}(111)$ system by Ferralis et $a l .{ }^{66}$. The present measurements give a direct proof of this effect. Chemical information is given by EDX measurements performed on both droplets type and also on the wetting layer. Figures 10 $\mathrm{D}, \mathrm{E}$ and $\mathrm{F}$ show the GeL, GeK and AuM lines intensity across the white line at selected points, for the bare surface (wetting layer), the droplet annealed at $350^{\circ} \mathrm{C}$ and the droplet annealed at $400^{\circ} \mathrm{C}$, respectively. As to the wetting layer, a very small Au signal is detected, in agreement with the formation of a diluted GeAu alloy. All models of the $\sqrt{3} \times \sqrt{3} \mathrm{R} 30^{\circ}$ reconstruction include only one $\mathrm{Au}$ atomic layer on top of the $\mathrm{Ge}(111)$. Furthermore, the strong interaction of that single Au layer with the substrate induces strong distortion of the Ge network underneath, as shown by $\mathrm{H}$. Over et al. by using dynamic LEED measurements ${ }^{50}$. These authors proposed Ge displacements up to the sixth atomic plane in the substrate. This could be at the origin of the contrast observed by TEM. Nevertheless, the extent of the wetting layer observed by TEM seems too large compared to that proposed in refs $48-50$. A part of the wetting layer observed by TEM could also be associated with in-plane Ge precipitation. This point deserves further investigation.

As to the droplets, Figure 10E and 10F show Ge and Au signals on droplets annealed at $350^{\circ} \mathrm{C}$, i.e. close to the eutectic temperature $\mathrm{T}_{\mathrm{E}}$, and at $400^{\circ} \mathrm{C}$. Figure $10 \mathrm{E}$ shows that $\mathrm{Au}$ signal is clearly sizeable for two points only, namely points 3 and 4 , thus in the droplet and above the wetting layer. In line with that, Ge signal is at his maximum for points 1 and 2, in the substrate or wetting layer and decreases strongly in the droplet. This graph shows that the 
Au content is almost the same at the droplet base and on the top of it. One can assume that the $\mathrm{Au}$ to Ge composition is quite uniform in the droplet upon annealing at $\mathrm{T}_{\mathrm{E}}$. In contrast, Figure $10 \mathrm{~F}$ shows that the Au signal strongly depends on position in the droplet. Indeed, a large $\mathrm{Au}$ signal is only measured at points 7 and 8 although the droplet extends from point 4 to point 8 . For points 5 and 6, a smaller Au signal is measured, larger that that at points 1 and 2, which are located in the substrate. These measurements clearly show that the vertical growth of the droplet is associated with a severe Au redistribution in it. The EDX profiles suggest that the Ge to Au composition is quite the same at the points at which AuM line is at maximum. At higher annealing temperature, a larger amount of $\mathrm{Ge}$ is incorporated in the droplet, which increases in height. From bulk phase diagram, the alloy composition changes from $\mathrm{Au}_{78} \mathrm{Ge}_{28}$ to $\mathrm{Au}_{74} \mathrm{Ge}_{32}$ when the annealing temperature is increases from $350^{\circ} \mathrm{C}$ to $400^{\circ} \mathrm{C}$. $\mathrm{Ge}$ incorporated during the annealing process is now precipitated along the surface plane, to give pedestal and/or wetting layer (this depends on the point of view, in-plane or cross-section) but also serves to increase the $\mathrm{Au}$ droplet height, as show in Figures 10F. Nevertheless, the composition variation from $\mathrm{Au}_{78} \mathrm{Ge}_{28}$ to $\mathrm{Au}_{74} \mathrm{Ge}_{32}$ upon increasing the temperature at $400^{\circ} \mathrm{C}$ seems too low to have such effect on the droplet shape and Ge distribution in it. This would only explain a height increase of about $4 \%$, i.e. far from that observed in Figure 10. This seems also suggested by the SEM tilted image shown in Figure 8 . The driving force for the longitudinal droplet growth is then Ge incorporation process during temperature increase, thus climbing the phase diagram liquidus/solidus (L-S) line, and Ge precipitation during temperature decrease, thus going down the L-S line. Nevertheless, this process alone cannot explain the large change in volume occupied by this extra Ge. Surface energy driven agglomeration has to be considered. The bulk phase diagram is modified upon decreasing the droplet size. Experimental evidence has been reported at the Au-Ge / Ge interface on top of a Ge nanowire ${ }^{23,28,72}$. It was found that for droplets with diameter lower that $100 \mathrm{~nm}$, an 
important change in the $\mathrm{Ge}$ at $\%$ is observed. This amounts at about $47 \%$ at $450^{\circ} \mathrm{C}$ instead of $32 \%$ for bulk material for a Ge nanowire diameter of $32 \mathrm{~nm}$. Nevertheless, this effect is much weaker for droplets with diameter of about $200 \mathrm{~nm}$ or more, as it is in the present work. Some important difference has although to be considered: in the present work, the droplet is in contact with a two-dimensional surface instead of a wire in ref.28. The present experiments suggest that this phenomenon could be enhanced on a two-dimensional surface. This opens the way to large surface modification, via significant material transport across the surface by using the peculiar properties of the binary or ternary alloys with a deep eutectic point in the bulk phase diagram.

\section{IV) Conclusion}

We have investigated the formation of Au-Ge seeds formed by Au layer dewetting on Ge(111) clean surface. We have shown that they are crystallized after melt and cooling down to room temperature. The Au platelets are in epitaxy on $\mathrm{Ge}(111)$ but epitaxy is lost after melt. As expected from bulk phase diagram, Au seeds incorporate Ge which precipitates to form a pedestal upon cooling down the sample at room temperature. The interesting feature here is that the Ge precipitated amount is larger (at least twice) that expected from bulk phase diagram opening the way to large surface modification, via significant material transport across the surface. 


\section{References}

[1] R. S. Wagner and W. C. Ellis, Appl. Phys. Lett. 4, 89 (1964)

[2] L. C. Chuang, M. Moewe, C, Chase, N. P. Kobayashi, C. Chang-Hasnain, S. Crankshaw , Appl. Phys. Lett. 90, 043115 (2007)

[3] Prokes, S. M.; Wang, K. L. Mater. Res. Sci. Bull. 24, 13 (1999).

[4] Duan, X.; Huang, Y.; Cui, Y.; Wang, J.; Lieber, C. M. Nature 409, 66 (2001).

[5] Cui, Y.; Lieber, C. M. Science 291, 851 (2001)

[6] A. M. Morales, C. M. Lieber, Science 279, 208 (1998).

[7] N. Wang, Y. H.Tang, Y. F. Zhang, C. S. Lee, , S. T. Lee, Phys. Rev.B.58, R16024 (1998).

[8] N. R. B. Coleman, M. A. Morris, T. R. Spalding, , J. D. J. Holmes, Am. Chem. Soc. 123, 187 (2001)

[9] Y. Wu, P. Yang, Chem. Mater. 12, 605 (2000).

[10] Y. F. Zhang, Y. H. Tang, N. Wang, C. S. Lee, I. Bello, S. T. Lee, Phys. Rev.B 61, 4518 (2000).

[11] H.Omi, T. Ogino, Appl. Phys. Lett. 71, 2163 (1997)

[10] N. R. B. Coleman, K. M. Ryan, T. R. Spalding, J. D. J. Holmes, M. A. Morris, Chem. Phys. Lett.343, 1 (2001).

[13] J. R. Heath, F. K. LeGoues, Chem. Phys. Lett. 208, 263 (1993).

[14] S. Kodambaka, J. Tersoff, M. C. Reuter, F. M. Ross, Science 316, 729 (2007)

[15] G. A. Bootsma, H. J. Gassen, J. Cryst. Growth 10, 223 (1971)

[16] H. Adhikari, A. F. Marshall, C. E. D. Chidsey, P. C. McIntyre, Nano Lett. 6, 318 (2006)

[17] Yajaira Sierra-Sastre, Shadi A. Dayeh, S. T. Picraux and Carl A. Batt, ACS Nano, 4, 1209, (2010) and J. Am. Chem. Soc. 130, 10489 (2008) 
[18] Ann F. Marshall, Irene A. Goldthorpe, Hemant Adhikari, Makoto Koto, Young-Chung Wang, Lianfeng Fu, Eva Olsson, and Paul C. McIntyre, Nano Lett.10, 3302 (2010)

[19] A. D. Gamalski, J. Tersoff, R. Sharma, C. Ducati,| and S. Hofmann, Nano Lett.10, 2972 (2010)

[20] H.Adhikari, A. F. Marshall, I. A. Goldthorpe, C. E. D. Chidsey, and P. C. McIntyre, Acnano 1, 415 (2007)

[21] S. A. Dayeh and S. T. Picraux, Nano Lett. 10, 4032 (2010)

[22] Y. Wu and P. Yang, J. Am. Chem. Soc. 123, 3165 (2001)

[23] E. Sutter and P. Sutter, Nanoletters 8, 411 (2008)

[24] H. Adhikari, A. F. Marshall, I. A. Goldthorpe, C. E. D. Chidsey, and P. C. McIntyre, ACS Nano 1, 415 (2007)

[25] X. Li, G. Meng, Q. Xu, M. Kong, X. Zhu, Z. Chu, and A.-P. Li, Nanoletters, in press.

[26)] K.Kang, D.A.Kim, H.S.Lee, C.J.Kim, J.E.Yang and M.H.Jo, Adv. Mat.20, 4684 (2008)

[27] M. Ge, J.F.Liu, H.Wu, C.Yao, Y.Zeng, Z.D.Fu, S.L.Zhang and J.Z.Jiang, J. Phys. Chem.C111, 11157 (2007)

[28] E. Sutter and P. Sutter, ACSNano4, 4943 (2010)

[29] K. W. Schwarz and J. Tersoff, Nano Lett.11, 316 (2011)

[30] V. G. Dubrovskii, G. E. Cirlin, N. V. Sibirev, F. Jabeen, J. C. Harmand and P. Werner, Nanoletters11, 1247 (2011)

[31] E. Sutter and P. Sutter, Adv. Mater.18, 2583 (2006)

[32] T. Hanrath and B. A. Korgel, J. Am. Chem. Soc. 124, 1424, (2002)

[33] P. C McIntyre, H. Adhikari, I.A Goldthorpe, S. Hu, P. W. Leu, A. F. Marshall and C. E. Chidsey, Semicond. Sci. Technol. 25, 024016 (2010)

[34] H.Adhikaria, P. C. McIntyre, A. F. Marshall, C. E. D. Chidsey, J. Appl. Phys. 102, $094311(2007)$ 
[35] W. H. Chen, R. Lardé, E. Cadel, T. Xu, B. Grandidier, J. P. Nys, D. Stiévenard, and P. Pareige, J. Appl. Phys. 107, 084902 (2010)

[36] Di Gao, R. He, C. Carraro, R. T. Howe, P. Yang, and R. Maboudian, J. Am. Chem. Soc.127, $4574(2005)$

[37] A. Kramer, T. Boeck, P. Schramm, R. Fornari, Physica E 40, 2462 (2008)

[38] Y. Homma, P. Finnie, and T. Ogino, H. Noda, T. Urisu, J. Appl. Phys.86, 3083 (1999)

[39] Y. Sierra-Sastre, S. Choi, S. T. Picraux, and C. A. Batt, J. Am. Chem. Soc. 130, 10488 (2008)

[40] S. N. Mohammad, J. Chem. Phys. 131, 224702 (2009)

[41] B. Fuhrmann, H. S. Leipner, and H.-R. Ho1che, L. Schubert, P. Werner, and U. Gösele, Nano Lett.5, 2524 (2005)

[42] T. Xu, J. P. Nys, A. Addad, O. I. Lebedev, A. Urbieta, B. Salhi, M. Berthe, B. Grandidier, and D. Stiévenard, Phys. Rev.B 81, 115403 (2010)

[43] Y. Margoninski and L.G. Feinstein, Surf. Sci. 23, 458 (1970)

[44] G. Le Lay, M. Manneville, J.J. Métois, Surf. Sci. Lett., 123, A445 (1982)

[45] G. Le Lay, M. Manneville, J.J. Métois, Surf. Sci., 123(1) 117 (1982)

[46] P. Perfetti, A. D. Katnani, R. R. Daniels, Te-Xiu Zhao and G. Margaritondo, Solid State Commun. 41, 213 (1982)

[47] L. Seehofer, R.L. Johnson, Surface Science 318, 21 (1994)

[48] P. B. Howes, C. Norris, M. S. Finney, E. Vlieg and R. G. van Silfhout, Phys. Rev. B 48, $1632(1993)$

[49] M. Göthelid, M. Hammar, M. Björkqvist, U. O. Karlsson, and S. A. Flodström, C. Wigren, G. LeLay, Phys. Rev. B 50, 4470 (1994)

[50] H. Over, C. P., Wang, F. Jona, Phys. Rev. B51, 4231 (1995) 
[51] A. Locatelli, A. Bianco, D. Cocco, S. Cherifi, S. Heun, M. Marsi, E. Bauer, J. Phys. IV 104, $99(2003)$

[52] A. Locatelli, L. Aballe, T.O. Mentes, M. Kiskinova, E. Bauer; Surf. Interface Anal. 38, 1554-1557 (2006)

[53] M. Derivaz, P. Noé, R. Dianoux, and A. Barski, T. Schülli and T. H. Metzger, Appl. Phys. Letters 81, 3843 (2002)

[54] R. T. Brewer and Harry A. Atwater, J. R. Groves and P. N. Arendt, J. Appl. Phys. 93, 205 (2003)

[55] J. T. Drotar, T.M. Lu, and G.C. Wang, J. Appl. Phys 96, 7071 (2004)

[56] Tao Feng, Hongbin Yu, Matthew Dicken, James R. Heath, and Harry A. Atwater, Appl. Phys. Lett. 86, 033103 (2005)

[57] Á. Nemcsics, Ch. Heyn, A. Stemmann, A. Schramm, H.Welsch, W. Hansen, Materials Science and Engineering B 165, 118 (2009)

[58] R. Krishnan, Y. Liu, C Gaire, L. Chen, G- C. Wang and T.M. Lu, Nanotechnology 21, $325704(2010)$

[59] R. M. Waghorne, V. G. Rivlin and G. I. Williams, J. Phys. F: Metal Phys.6, 147 (1976)

[60] R. P. Elliott and F. A. Shunk, Journal of Phase Equilibria 1, 51 (1980)

[61] Binary Alloy Phase Diagrams, 2nd ed.; ASM International: Materials Park, OH, 1990; Vol. 1.

[62] D. Hourlier, P. Perrot, Materials Science Forum, 653, 77 (2010)

[63] P.Wetzel, C. Pirri, P. Paki, D. Bolmont and G. Gewinner, Phys. Rev. B47, 3677 (1993)

[64] P. Wetzel, C. Pirri and G. Gewinner, Europhys. Lett. 38, 359 (1997)

[65] B. Ressel, K. C. Prince, and S. Heun, Y. Homma, J. Appl. Phys.93, 3886 (2003)

[66] N. Ferralis, R. Maboudian, and C. Carraro, J. Am. Chem. Soc. 130, 2683 (2008) 
[67] N. Ferralis, F. El Gabaly, A. K. Schmid, R. Maboudian,1 and C. Carraro, Phys. Rev. Lett. 103, 256102 (2009)

[68] S. Shukla and S. Seal, Nano Structured Materials 11, 1181 (1999)

[69] A. Tanaka, Y. Takeda, T. Nagasawa, K.Takahashi, Solid State Commun.126, 191 (2003)

[70] A. Tanaka, Y. Takeda, M. Imamura, S. Sato, Phys. Rev.B 68, 195415 (2003)

[71] T. Ohgi , D. Fujita, Surface Science 532-535, 294-299 (2003)

[72] P.W. Sutter and E.A. Sutter, Nature Materials 6, 363 (2007) 


\section{Figures captions:}

Figure 1: (A) STM image of $0.8 \mathrm{~nm}$ Au deposited onto a room-temperature (RT) clean $\mathrm{Ge}(111)$. (B) $\mathrm{Au} 4 \mathrm{f}_{7 / 2}$ XPD profiles versus polar angle $\theta$ along the [11-2], [10-1] and [-1-12] direction of the $\mathrm{Ge}(111)$ substrate.

Figure 2: (A) STM images of $0.8 \mathrm{~nm}$ Au deposited onto a room-temperature (RT) clean $\mathrm{Ge}(111)$ annealed for $10 \mathrm{~min}$ at $300^{\circ} \mathrm{C}$. Also shown in this image is a line profile across islands. (B) $\mathrm{Au} 4 \mathrm{f}_{7 / 2}$ XPD profile versus polar angle $\theta$ along the [11-2] direction of the $\mathrm{Ge}(111)$ substrate measured on the $\mathrm{Au}$ deposit annealed at $300^{\circ} \mathrm{C}$ (a) and on the roomtemperature deposited Au layer (b).

Figure 3: STM images of $0.8 \mathrm{~nm}$ Au deposited onto a room-temperature (RT) clean Ge(111) annealed for $10 \mathrm{~min}$ at $325^{\circ} \mathrm{C}$. Also shown in this image is a line profile which clearly distinguishes flat and dome-like islands.

Figure 4: STM images of $0.8 \mathrm{~nm}$ Au deposited onto a room-temperature (RT) clean Ge(111) annealed for $10 \mathrm{~min}$ at $350^{\circ} \mathrm{C}$. Also shown in this image is a line profile across a dome-like island.

Figure 5: (A) STM image of $0.8 \mathrm{~nm}$ Au deposited after 12 hours annealing at $350^{\circ} \mathrm{C}$ and (B) a detail of a droplet. (C) $\mathrm{Au} 4 \mathrm{f}_{7 / 2}$ XPD profiles versus polar angle $\theta$ along the [11-2] direction of the $\mathrm{Ge}(111)$ substrate measured on the room-temperature (RT) (a), on the Au deposit annealed at $300^{\circ} \mathrm{C} \mathrm{(b)} \mathrm{and} \mathrm{on} \mathrm{the} \mathrm{Au} \mathrm{deposit} \mathrm{annealed} \mathrm{at} 350^{\circ} \mathrm{C}$ (c). 
Figure 6: A) STM images $(2 \mu \mathrm{m} \times 2 \mu \mathrm{m})$ of an Au deposit of $0.4 \mathrm{~nm}, 0.8 \mathrm{~nm}$ and $1.2 \mathrm{~nm}$ annealed at $350^{\circ} \mathrm{C}$ for $10 \mathrm{~min}$. Also shown for a $0.8 \mathrm{~nm} \mathrm{Au}$ deposit annealed at $350^{\circ} \mathrm{C}$ : B) the droplets diameter versus the annealing time, C) the droplets height versus annealing time and E) the proportion of the surface covered by droplets versus annealing time.

Figure 7: RHEED pattern measured on a $1.2 \mathrm{~nm}$ thick Au layer annealed at $350^{\circ} \mathrm{C}$. The primary energy is $30 \mathrm{keV}$ and the angle of incidence is $<0.77^{\circ}$ from the surface.

Figure 8: SEM images collected at room temperature for a $1.2 \mathrm{~nm}$ Au deposit after anneal at $350^{\circ} \mathrm{C}(\mathrm{A})$ and $400^{\circ} \mathrm{C}(\mathrm{B}, \mathrm{C}, \mathrm{D})$ for 1 hour. The topmost images (A) and (B) are $45^{\circ}$ tilted images to enhance the observation of the pedestal.

Figure 9: (A) XPEEM image of the sample surface for $1.2 \mathrm{~nm} \mathrm{Au}$ deposit annealed at $350{ }^{\circ} \mathrm{C}$ for 12 hours. This image acquired in the XPS mode. The sample is illuminated at photon energy of $201 \mathrm{eV}$ and the lateral distribution of the Au4f intensity is taken at a kinetic energy of $E_{c}=113 \mathrm{eV}$, thus at the $A u 4 f_{7 / 2}$ line maximum. The field of view is $4 \mu \mathrm{m}$. (B) Normalized Au4f lines measured on droplets (a) and surface in between (b).

Figure 10: Cross-section TEM images for a $1.2 \mathrm{~nm}$ Au deposit annealed at $350^{\circ} \mathrm{C}$ and $400^{\circ} \mathrm{C}$. This figure also shows the GeL, GeK and AuM $\alpha$ lines intensity across the yellow line of the cross-section images at selected points. 

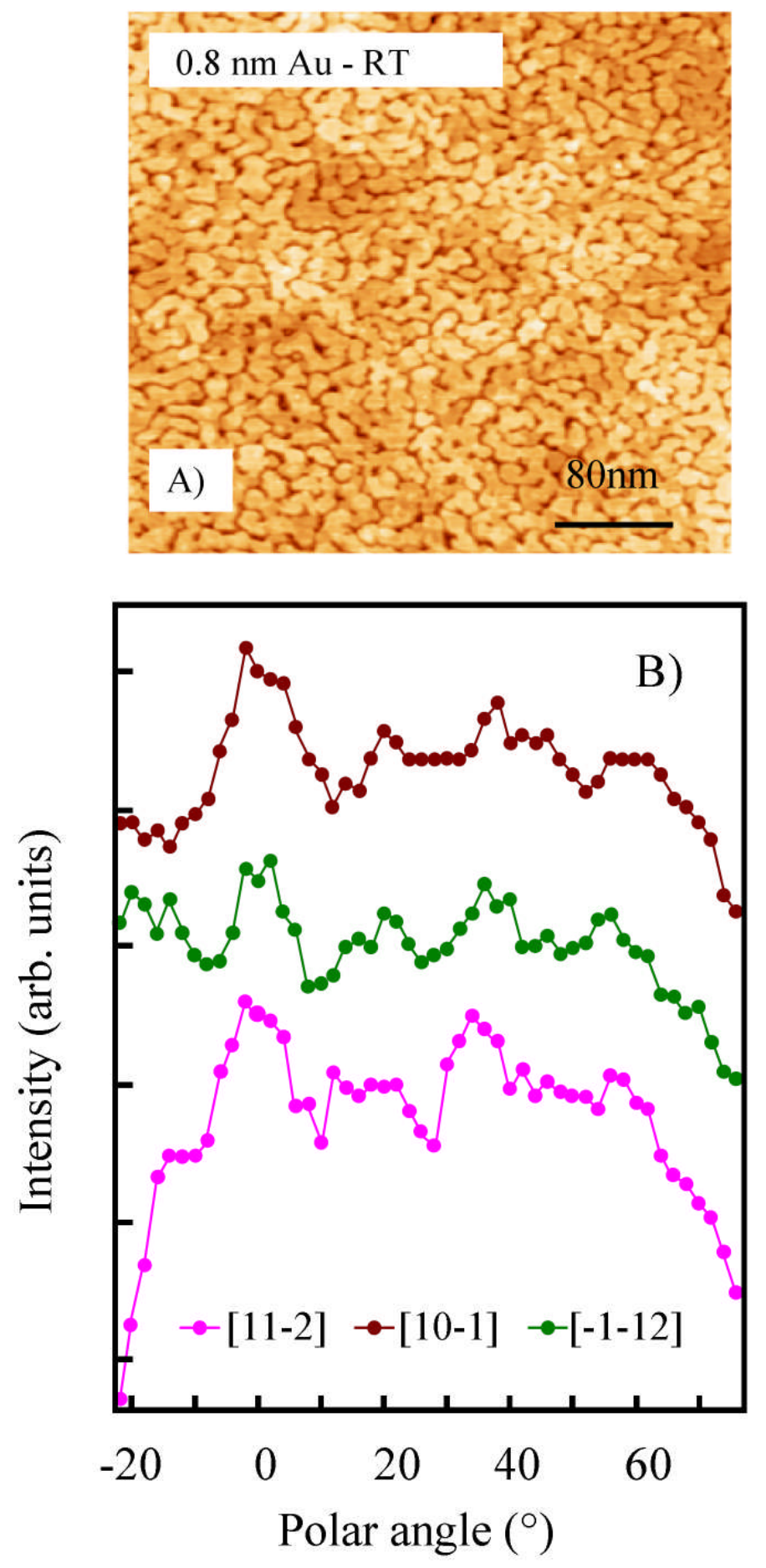

Figure 1 

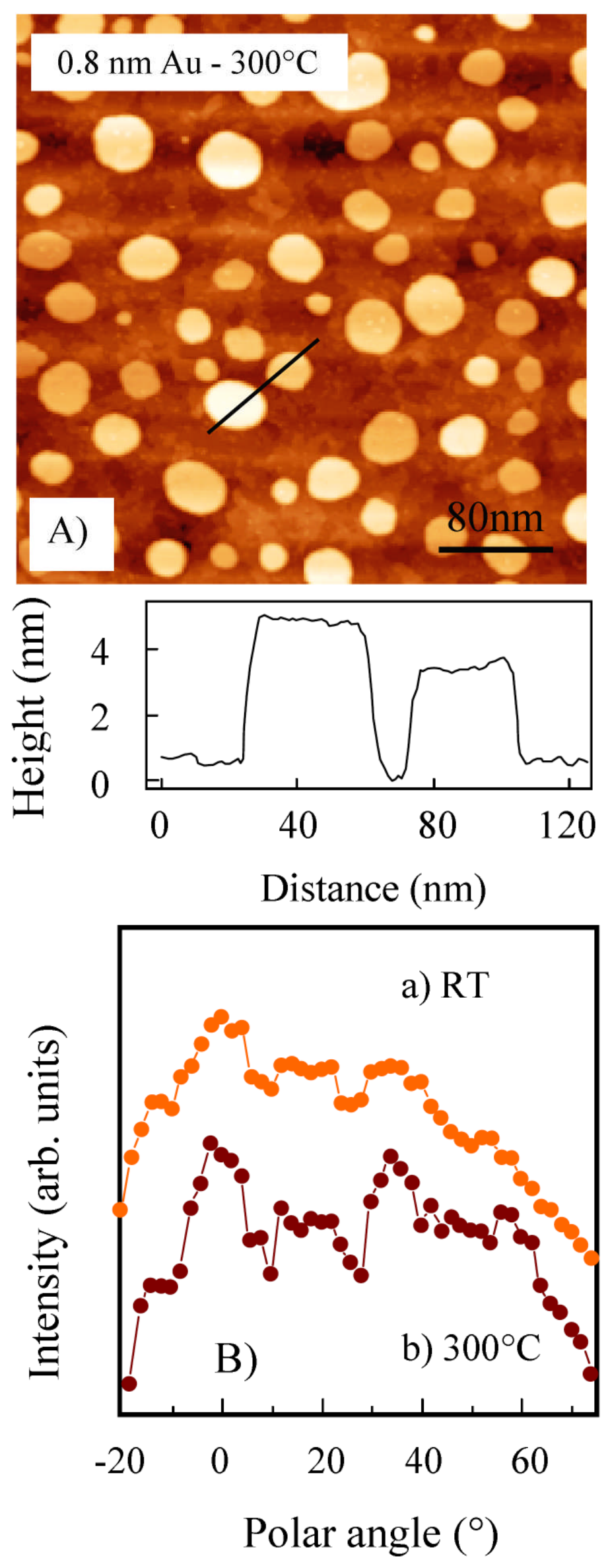

Figure 2 

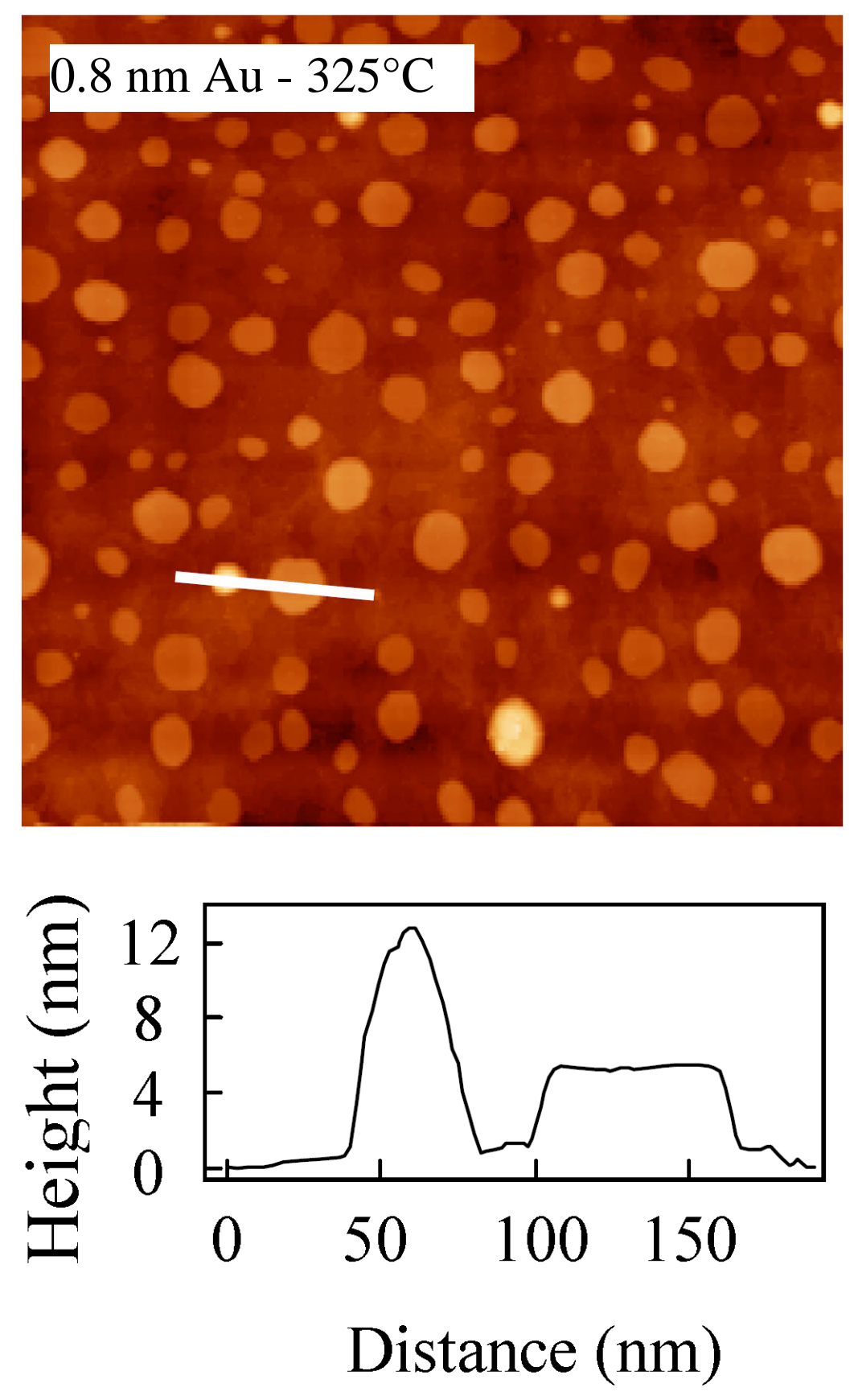

Figure 3 

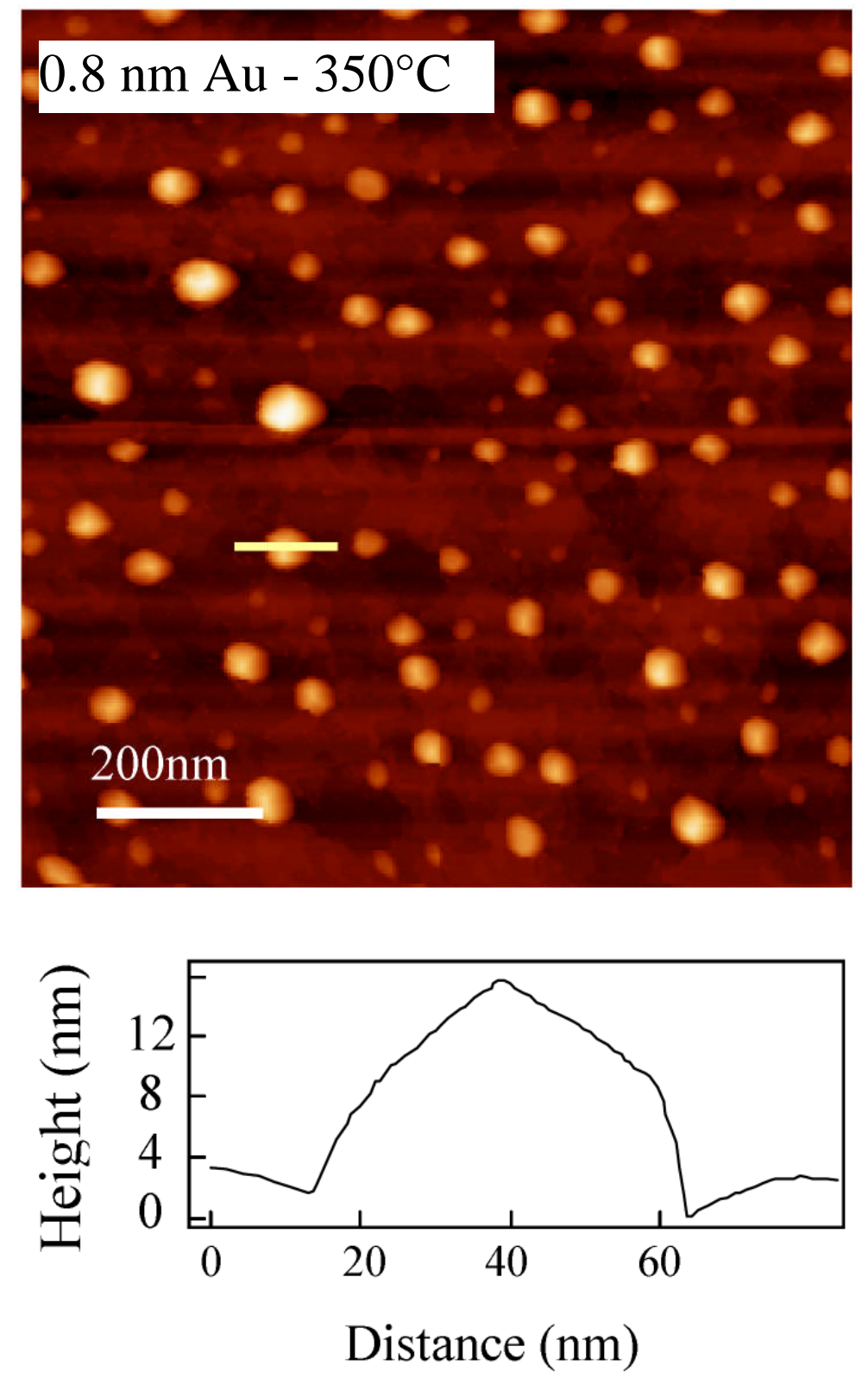

Figure 4 

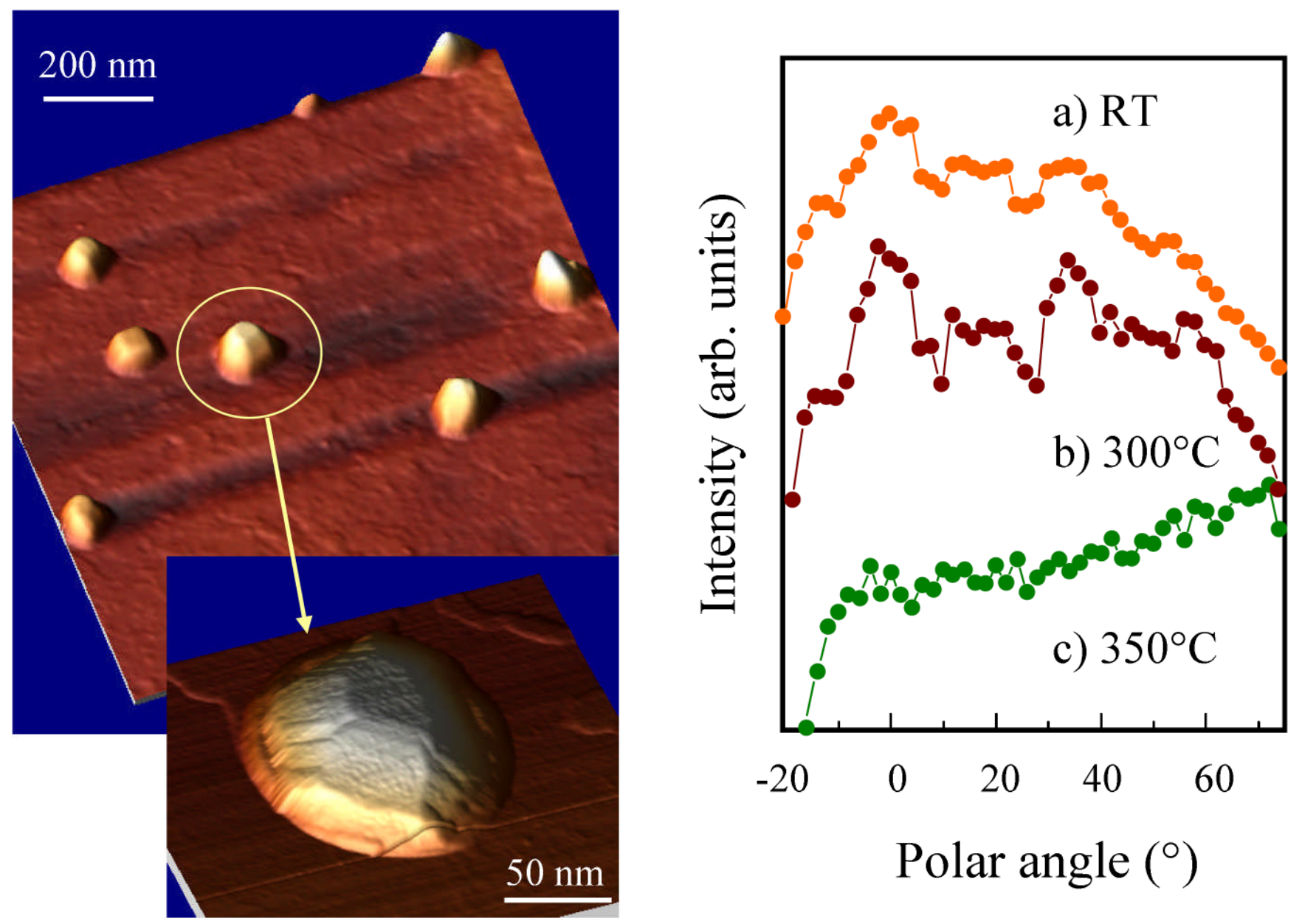

Figure 5 

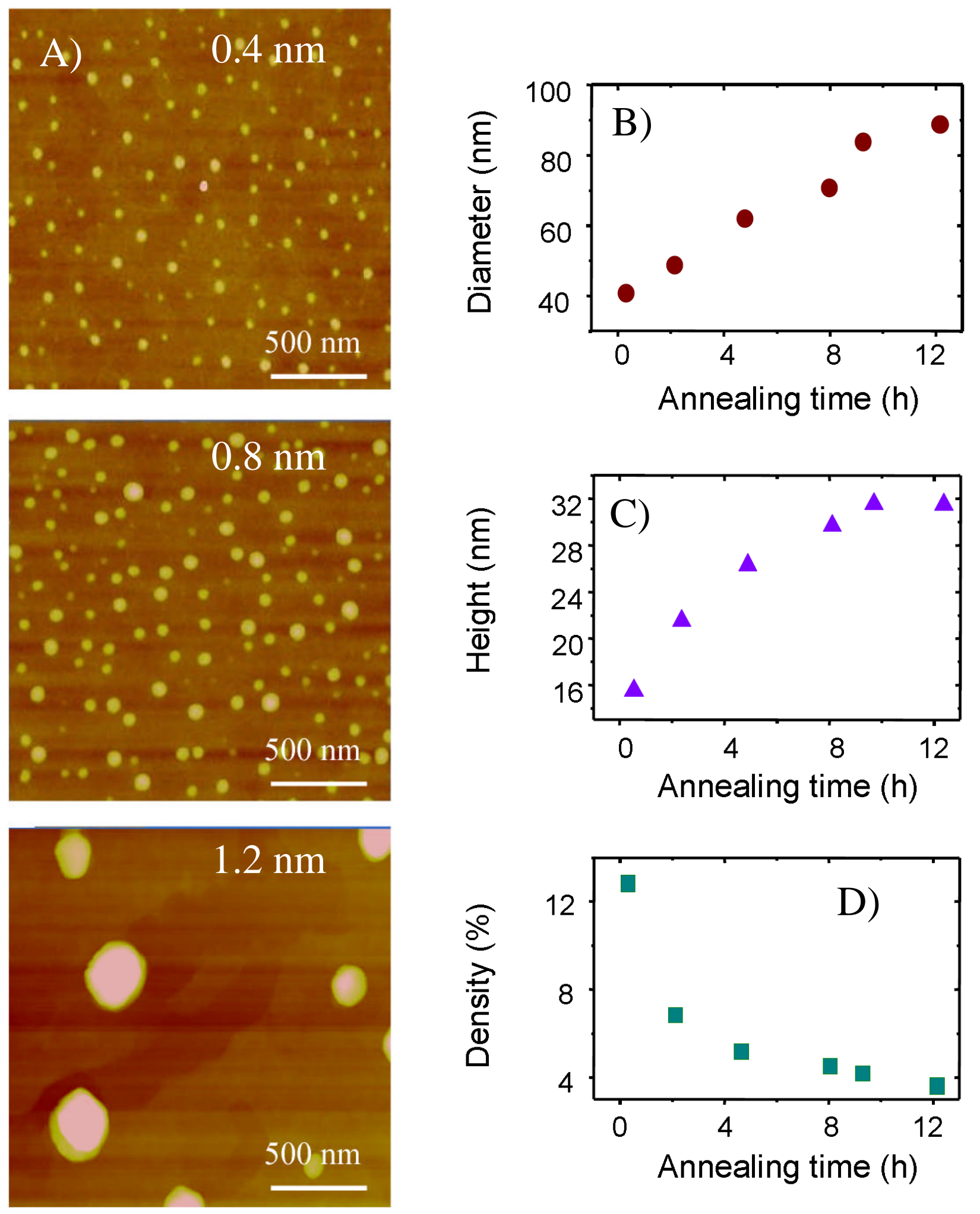

Figure 6 

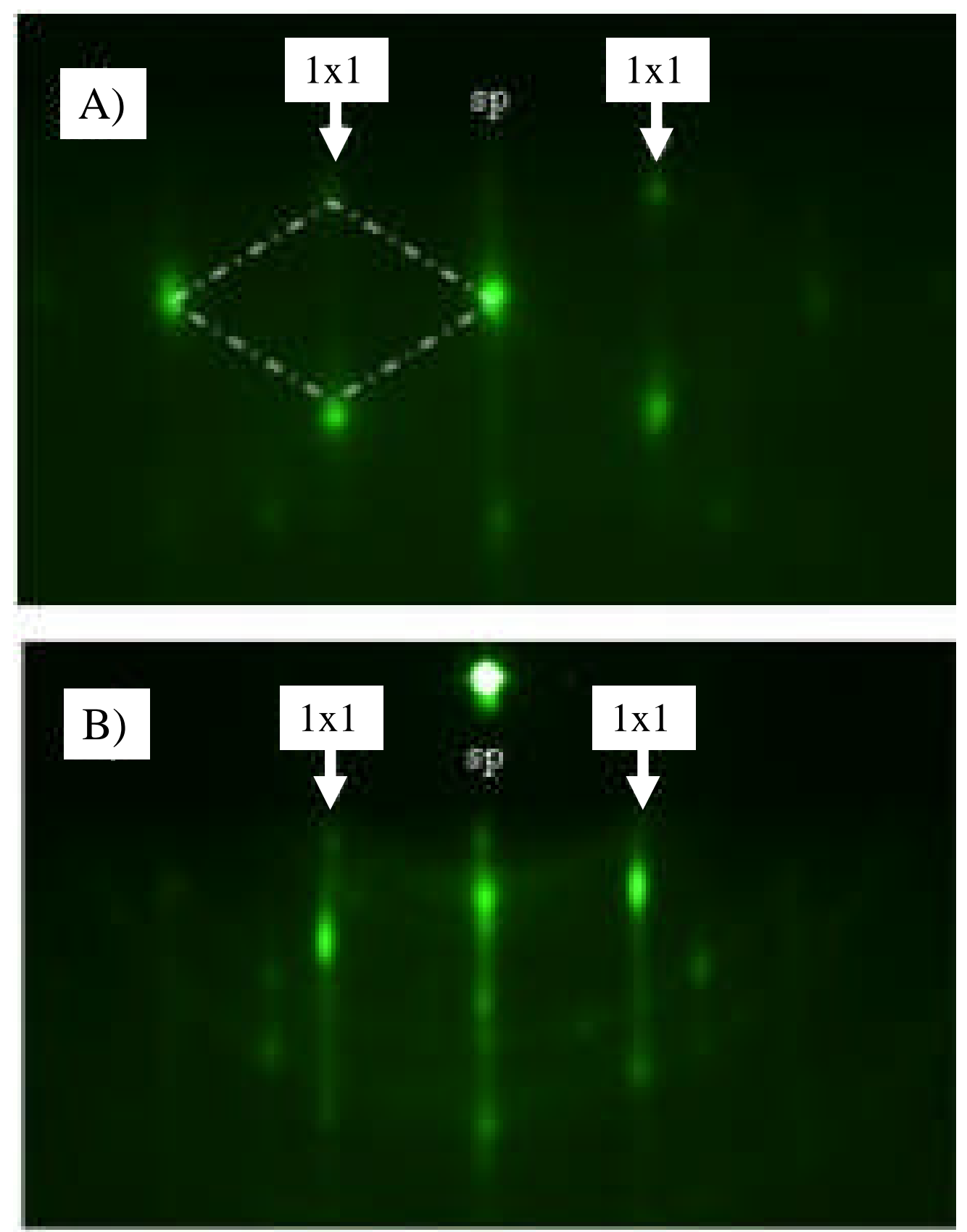

Figure 7 

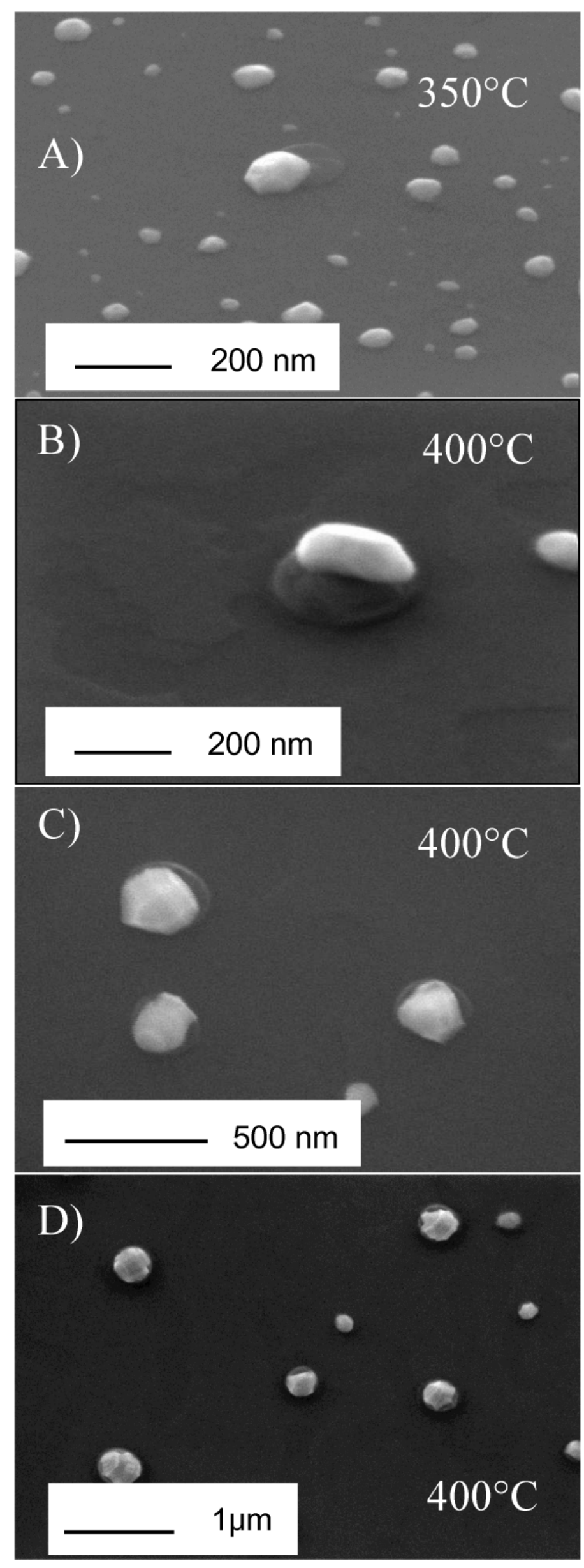

Figure 8 

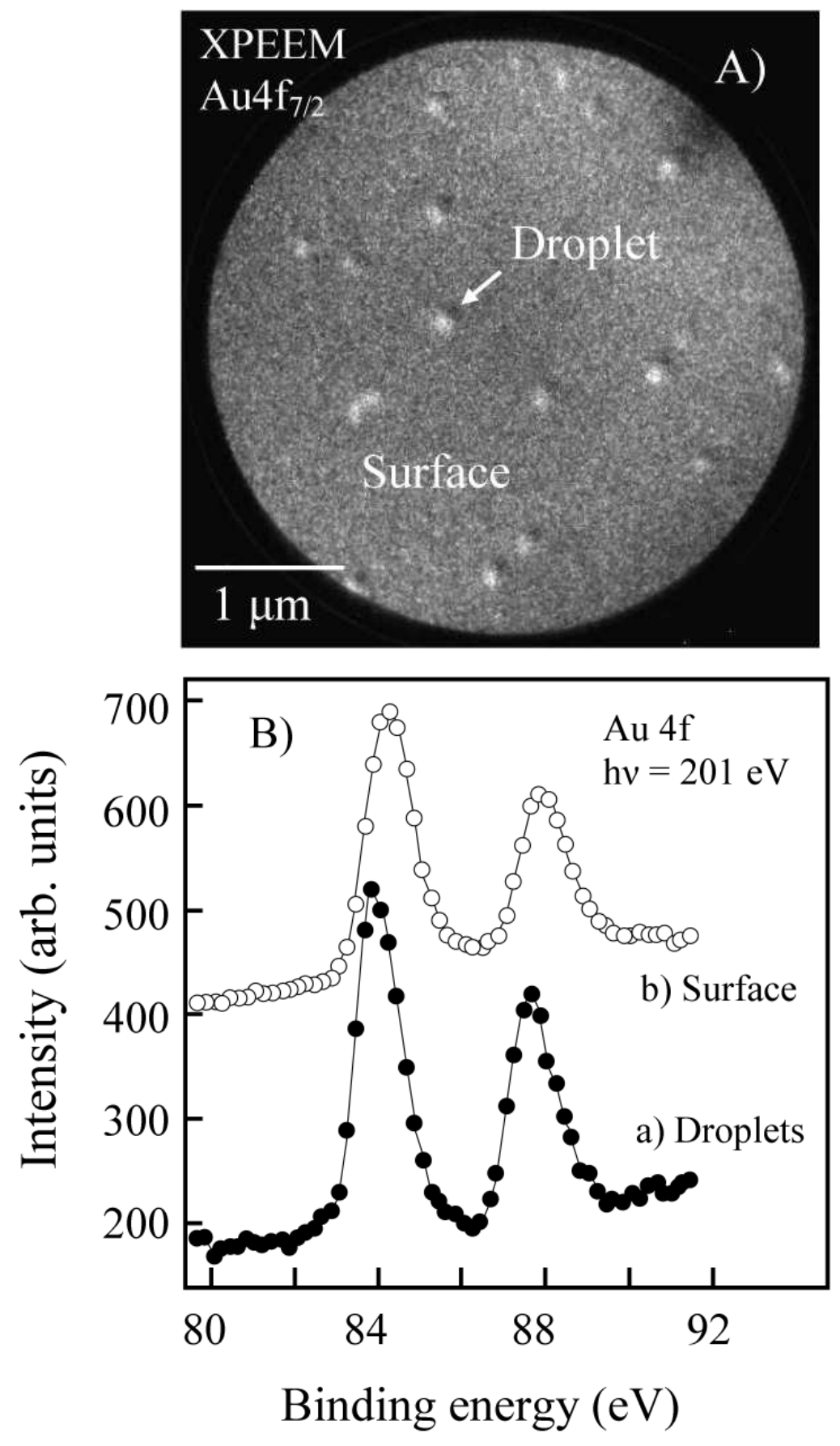

Figure 9 

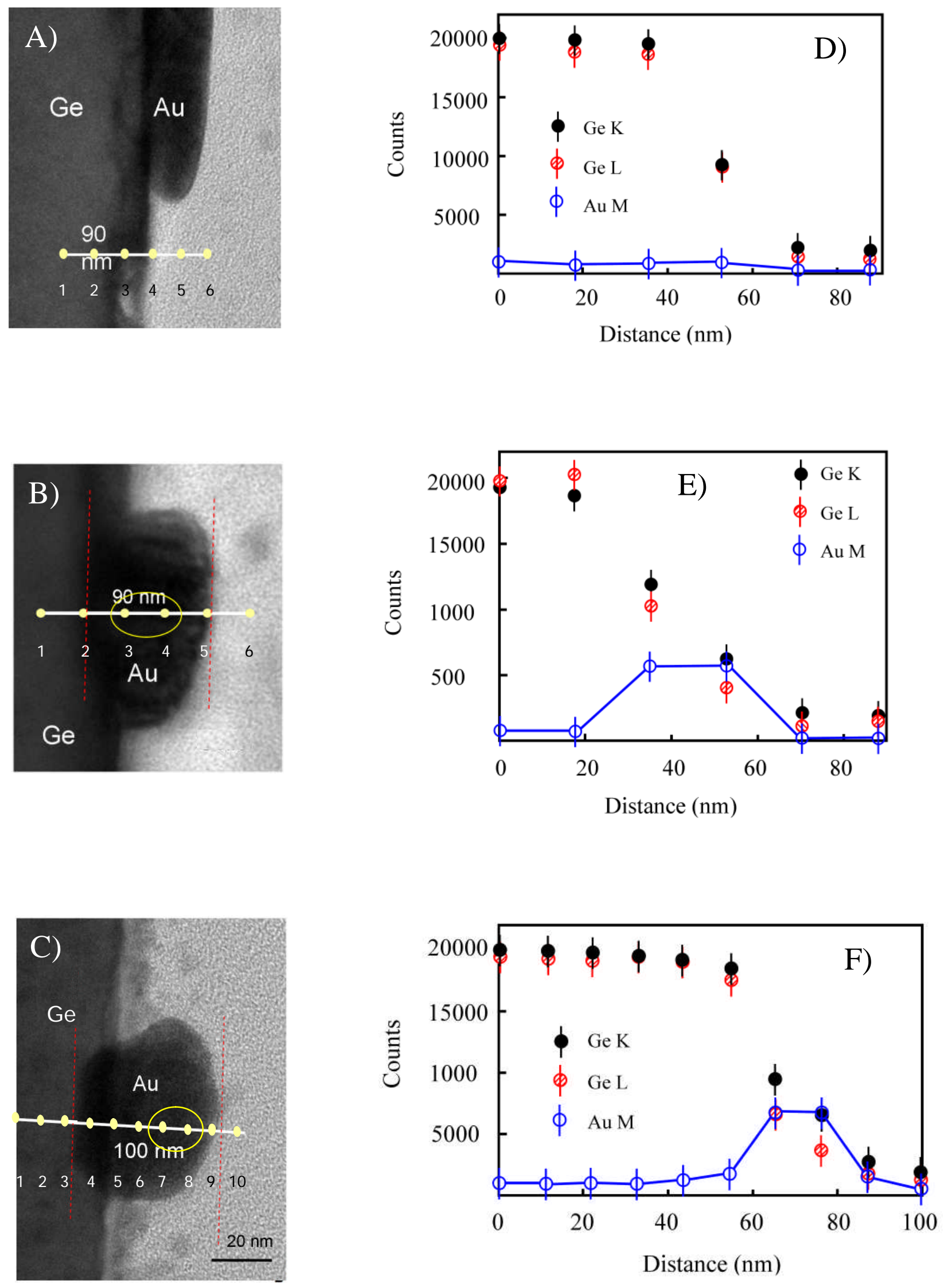

Figure 10 